\title{
PERSISTENCE OF CIVIL WARS
}

\author{
Daron Acemoglu \\ MIT
}

\author{
Andrea Vindigni \\ Princeton University
}

\author{
Davide Ticchi \\ University of Urbino
}

\begin{abstract}
A notable feature of post-World War II civil wars is their very long average duration. We provide a theory of the persistence of civil wars. The civilian government can successfully defeat rebellious factions only by creating a relatively strong army. In weakly institutionalized polities this opens the way for excessive influence or coups by the military. Civilian governments whose rents are largely unaffected by civil wars then choose small and weak armies that are incapable of ending insurrections. Our framework also shows that when civilian governments need to take more decisive action against rebels, they may be forced to build oversized armies, beyond the size necessary for fighting the insurrection, as a commitment to not reforming the military in the future. (JEL: H2, N10, N40, P16)
\end{abstract}

\section{Introduction}

One of the most striking facts of post-World War II international politics is the unusually long average duration of civil wars. ${ }^{1}$ Some scholars (e.g., Hironaka 2008) argue that this is largely due to the proliferation of politically weak states since World War II and the onset of decolonization. Although the link between

\footnotetext{
The editor in charge of this paper was Fabio Canova.

Acknowledgments: We thank Roland Bénabou, Pierre Yared, Fabrizio Zilibotti, and conference participants in EEA Barcelona 2009 for comments. Acemoglu gratefully acknowledges financial support from the NSF. Ticchi gratefully acknowledges financial support from the MIUR. Vindigni gratefully acknowledges the hospitality of Einaudi Institute for Economics and Finance. Acemoglu is a member of CIFAR.

E-mail addresses: Acemoglu: daron@mit.edu; Ticchi: davide.ticchi@ uniurb.it; Vindigni: vindigni@ princeton.edu

1. Civil wars during the 19 th and early 20 th century were usually relatively short; the average length of a civil war between 1900 and 1944 was 1.5 years. After World War II, the average duration of civil wars has tripled to over 4 years. The number of ongoing civil wars has also increased dramatically since 1945. For example, an average of about 20 civil wars per year were ongoing concurrently in the 1990s, corresponding to a rate approximately ten times the historical average since the 19th century. The surge in the number of ongoing civil wars has been mainly due to the increase in average duration rather than in the rate of outbreak of new conflicts. See Hironaka (2008).
} 
politically weak states (which lack the Weberian monopoly of violence) and persistence of civil wars is compelling, it raises another major question: Why has the political weakness of many post-World War II states persisted?

We provide an explanation for why civil wars may persist in weakly institutionalized polities. Central to our explanation is the political moral hazard problem generated by a strong military (Acemoglu, Ticchi, and Vindigni 2010a). In weakly institutionalized polities, the checks to prevent a strong military from intervening in domestic politics are absent. This makes the building of a strong army a double-edge sword for many civilian governments, even if such an army is necessary for defeating rebels and establishing the monopoly of violence.

We formalize these ideas using a simple dynamic game. The civilian government is controlled by an elite, which derives rents from holding power. It faces armed rebellion from an opposition group (e.g., a group of different ethnicity or religion). The minimum scale of the army is insufficient for ending this armed rebellion and establishing the monopoly of violence. The elite can instead choose a larger size army, which will end the civil war, but this will also increase the role of the military in domestic politics. The civilian government-military interaction is complicated by the fact that the elite cannot credibly commit to not reforming and downsizing the military once the civil war is over. Consequently, a stronger military, which is necessary for defeating the rebels, may also attempt a coup. Thus the elite often face a choice between a persistent civil war versus the risk of a coup. Our framework also points out another strategy for the elite: To build an over-sized army as a commitment to not reforming the military after the end of the civil war (since the over-sized army is strong enough to resist any attempt to reform). This suggests that in weakly institutionalized polities both the persistence of civil wars and the emergence of over-sized armies with excessive influence on domestic politics are possible equilibrium outcomes. ${ }^{2}$

Our analysis shows that when the elite's rents are relatively unaffected by its lack of monopoly of violence-for example, because the civil war is in a remote area or it does not interfere with their control of natural resources- then the elite will be unwilling to build a strong army. In contrast, when the rebels pose a more costly threat to their rents, the elite is more likely to build a strong army, either risking the possibility of a coup after the end of the civil war or accepting excessive concessions to an over-sized army.

2. An illustrative example of a regime unwilling to build a strong army despite ongoing civil wars, most likely because of fear of increasing the power of the military in the future, is Zaire (Congo) under Mobutu. An example of a regime building a strong army to fight communist rebels and then facing a coup is the Philippines under Marcos. Examples of regimes building over-sized armies that have received significant concessions but have not attempted coups are provided by Egypt, Iraq, and Syria starting in the 1960s (e.g., Owen 2004). Interestingly, the Egyptian military attempted a coup precisely when President Sadat tried to downsize it. 
Our framework also generates a novel substitutability between fiscal and political capacity of the state. Although these capacities are generally thought to be complements (e.g., Besley and Persson 2009), in our model higher fiscal capacity raises the equilibrium cost of building strong armies (because it makes military dictatorships both more likely and more costly to the elite) and via this channel, it contributes to the persistence of civil wars.

Our work is related to several different literatures in comparative politics. The large literature on the causes of civil wars is surveyed in Blattman and Miguel (2010). Fearon and Laitin (2003) and Herbst (2004) emphasize the role of weak states in the emergence of civil wars, and Fearon (2007), Powell (2004), and Yared (2009) analyze the duration of civil wars. Our paper is also related to the small economics literature on weakly institutionalized polities, the problems of weak states, and the analysis of state formation, including Acemoglu, Robinson, and Verdier (2004), Acemoglu (2005), Acemoglu, Ticchi, and Vindigni (2010b), and Besley and Persson (2009), and to the political economy literature on regime transitions (see, e.g., Acemoglu and Robinson 2006). Our analysis of the political moral hazard problem between the civilian government and the military builds on Acemoglu, Ticchi, and Vindigni (2010a). The closely related and complementary work by Besley and Robinson (2010) also emphasizes the cost of concessions that the civilian government must make to the military and analyzes the choice between strong armies and "tin pot" militaries.

\section{The Model}

We consider a society consisting of four social groups: the elite, $E$, the citizens, $L$, the rebels, $\Re$, and the military, $M$. Each agent $j$ at time $t=0$ maximizes $\mathbb{E}_{0} \sum_{t=0}^{\infty} \beta^{t}\left(c_{j, t}+r_{j, t}\right)$, where $\mathbb{E}_{0}$ is the expectation at time $t=0$, $\beta \in(0,1)$ is the discount factor, $c_{j, t} \geq 0$ denotes the consumption of the final good (equal to disposable income), and $r_{j, t} \geq 0$ is a rent appropriated by each individual whose group is in power at time $t$, representing non-monetary payoffs from holding power or returns from natural resources or other income sources.

The size of the elite is normalized to 1 . The size of the citizens is equal to $n$, while the size of the military, which will be determined endogenously, is $x_{t}$ at time $t$. For simplicity, we assume that only the citizens are recruited into the army, and that $x \in\left\{x_{\ell}, x_{m}, x_{h}\right\}$, where $x_{\ell}<x_{m}<x_{h}<n$. The minimum size of the army, $x_{\ell}$, is necessary for maintaining law and order and national defence. An army of a size larger than the minimum level $x_{\ell}$ can be chosen to deal with the rebels as explained further subsequently. For reasons that will become obvious shortly, we refer to $x_{h}$ as an "over-sized army." Each elite agent has productivity $a$, and each citizen has a productivity $A<a$. Citizens recruited into the military do not produce any income. 
There are three political states $s_{t} \in\{W, D, M\} ;{ }^{3} \mathrm{~W}$ is a civilian regime with civil war (rebellion); $D$ is a civilian regime (democracy) without rebellion; and $M$ is a military dictatorship. The civilian government, with or without rebellion, is ruled by the elite (e.g., a captured democracy or an oligarchy). In a military dictatorship, the military commander (or a group of officers) is in power. Because our focus is on the persistence of civil wars, we assume that the initial political state is $s_{0}=W$; that is, a civilian regime under a rebellion. If the rebellion is defeated, there will be a transition to $s=D$, but the military can attempt a coup against democracy and cause a transition to $s=M$. To simplify the analysis, we assume that the military dictatorship is absorbing (i.e., once $s=M$, this will apply in all future dates) and that a military coup is not possible starting from $s=W$ (so that possible transitions are $W \rightarrow D \rightarrow M$ ).

Both civil war and coups cause economic inefficiencies. Civil war disrupts economic transactions and reduces all incomes by a factor $\delta \in[0,1]$, so that the income of each elite becomes $(1-\delta) a$ and that of each citizen is $(1-\delta) A$. Similarly, the military is not equipped to run the economy, and thus under a military dictatorship, all incomes are reduced by a factor $\phi \in[0,1]$.

The government collects revenues with proportional taxation $\tau_{t} \in[0,1]$, and these revenues are used to pay the salaries of soldiers. We model tax distortions in a simple way, assuming that there are no costs of taxation until some rate $\hat{\tau}>0$, and after $\tau=\hat{\tau}$, taxation is prohibitively costly (this makes $\hat{\tau}$ the peak of the Laffer curve). The government budget constraint, which must be satisfied at each period, thus takes the form

$$
w\left(x_{t} \mid s_{t}\right) x_{t} \leq \tau\left(x_{t} \mid s_{t}\right)\left(a_{t}+\left(n-x_{t}\right) A_{t}\right),
$$

where $w\left(x_{t} \mid s_{t}\right)$ and $\tau\left(x_{t} \mid s_{t}\right)$ denote the military wage and the tax rate with an army of size $x_{t}$ in the political state $s_{t}$.

We next describe transitions in greater detail. As noted previously, we start in $s_{0}=W$. There is a transition to $s=D$ when the rebellion (civil war) is defeated, and for simplicity, there is no further possibility of another rebellion. The probability that the rebellion will be defeated is a function of the strength of the state (the size of the army). In particular, we assume that the civil war ends with probability $p(x) \in[0,1]$ in each period, where $p\left(x_{\ell}\right)=p<p\left(x_{m}\right)=p\left(x_{h}\right)=1$. This implies that when $x_{t}=x_{\ell}$, there is a "high likelihood," probability $1-p$, that the civil war will persist because of the weakness of the state. In contrast, a moderate or an over-sized army is sufficient to end the civil war immediately. In addition, however, strong armies, $x \in\left\{x_{m}, x_{h}\right\}$, can undertake a coup against the civilian government once the civil war is defeated. This makes them a doubleedge sword for the incumbent civilian government, for they defeat the rebels,

3. Payoff-relevant states will be given by elements of $\{W, D, M\} \times\left\{x_{\ell}, x_{m}, x_{h}\right\}$. 
but may attempt a coup after the end of the conflict. The difference between the intermediate-sized strong army, $x_{m}$, and the over-sized strong army, $x_{h}$, is that the former can be downsized by the civilian government, and the probability that a civilian government can do this within any given period is equal to $\lambda \in[0,1]$. In contrast, an over-sized army, $x=x_{h}$, is strong enough to withstand any attempt to reform and can thus never be reformed and downsized by a civilian government. $\varphi_{t} \in\{0,1\}$ denotes the state of the world at time $t$ where an intermediate-sized army can $\left(\varphi_{t}=0\right)$ or cannot $\left(\varphi_{t}=1\right)$ be reformed. The initial size of the military, $x_{0}$, is decided by the civilian government at the beginning of time $t=0$.

We also assume that each soldier has to put effort, which costs $h>0$, in fighting the rebels. If he does not do so, he is caught with probability $q \in(0,1)$, and is punished by losing his wage for one period. This imperfect monitoring technology will lead to "efficiency wages" for soldiers during times of civil war.

We represent the economy described so far as a dynamic game between the soldiers and the elite. ${ }^{4}$ More formally, the timing of events starting in $s_{t}=W$ or $D$ is as follows:

1. The civilian government chooses the size $x_{t}$ of the army, sets taxes $\tau_{t}$ and military wages $w_{t}$ subject to the budget constraint (1) and the constraint that $x_{t}=x_{t-1}$ whenever $x_{t-1}=x_{h}$ or whenever $\varphi_{t}=1$ (i.e., the state of the world at time $t$ is such that the army cannot be reformed). Then:

2. If $s_{t}=W$, then rebels are defeated with probability $p\left(x_{t}\right)$ and the civil war ends permanently, inducing a transition to $s_{t+1}=D$. Otherwise, $s_{t+1}=W$, and the same sequence of events is repeated. If, instead, $s_{t}=D$, then: When $x_{t-1}=x_{m}$ and the state of the world is such that the military can be reformed $\left(\varphi_{t}=0\right)$, the civilian government decides whether or not to reform it (if there is no reform, then $x_{t}=x_{m}$ ). When $x_{t}=x_{m}$ or $x_{t}=x_{h}$, the military decides whether to attempt a coup against the civilian government. A coup succeeds with probability 1 , inducing a transition to $s_{t}=M$.

Finally, in state $s_{t}=M$, which is absorbing, the military government chooses taxes and military wages subject to the government budget constraint (1).

\section{Characterization of Equilibria}

We next characterize the Markov Perfect Equilibrium (MPE) of this dynamic political game. We start in the political state $s=W$. Because fighting against the rebels requires an effort cost $h$ for each soldier and shirking is detected only

4. The rebels and the citizens do not play an active role because of our simplifying assumptions, and there is no conflict within groups, so that we can suppose that decisions are taken by a representative agent from each group (e.g., the commander of the army and a representative elite agent in a civilian government). 
with probability $q$, the incentive compatible equilibrium military wage during the civil war needs to be at least $h / q$ (see Acemoglu, Ticchi, and Vindigni 2010b). We assume that this wage also satisfies the participation constraint ensuring that citizens are weakly better off as soldiers than as producers (for example, $h / q \geq$ $\left(1-\bar{\tau}_{\ell}\right) A$, with $\bar{\tau}_{\ell}$ defined in equation (2), would be sufficient for this). Given the income disruptions due to civil war, the tax rate that satisfies the government budget constraint (1) is

$$
\bar{\tau}_{i}=\frac{x_{i}}{(1-\delta)\left(a+\left(n-x_{i}\right) A\right)} \frac{h}{q} \quad \text { for } i \in\{\ell, m, h\},
$$

provided that this tax rate is less than the maximum feasible rate, $\hat{\tau}$.

Next consider the political state $s=D$. If $x=x_{\ell}$, then coups are not feasible and effort is no longer necessary, thus military wages will be determined by the participation constraint, which makes a soldier indifferent between working as a civilian and working as a soldier-that is, $w_{\ell}=\left(1-\tau_{\ell}\right) A$, where $\tau_{\ell}$ is the equilibrium tax rate in this case. Consequently, the value of a soldier and the value of a civilian under democracy and $x=x_{\ell}$ are

$$
V^{M}\left(D, x_{\ell}\right)=V^{L}\left(D, x_{\ell}\right)=\frac{\left(1-\tau_{\ell}\right) A}{1-\beta},
$$

where the tax rate $\tau_{\ell}$ balancing the government budget (1) is $\tau_{\ell}=x_{\ell} A /(a+n A)$.

When $x \in\left\{x_{m}, x_{h}\right\}$, the army may attempt a coup against the democratic government in the state $s_{t}=D$, that is, after the rebels have been defeated. Consequently, in these cases the elite need to take into account the strategy of the military to set fiscal policy. In particular, as in Acemoglu, Ticchi, and Vindigni (2010a), there will be a no coup constraint of the form,

$$
V^{M}\left(D, x_{i} \mid \text { coup }\right) \leq V^{M}\left(D, x_{i} \mid \text { no coup }\right) \quad \text { for } i \in\{m, h\},
$$

which the elite must satisfy if they wish to prevent coups; $V^{M}\left(D, x_{i} \mid\right.$ coup $)$ and $V^{M}\left(D, x_{i} \mid\right.$ no coup $)$ denote the values of soldiers with an army size of $x_{i}$ when they undertake a coup and when they choose not to do so. To derive the implications of the no coup constraint, first consider a military regime, and let $R$ denote the rents that soldiers receive in such a regime. Because this regime is absorbing and there are no costs of taxation until $\hat{\tau}$, soldiers will set $\tau=\hat{\tau}$ and redistribute the proceeds as wages to themselves, so that

$$
V^{M}\left(M, x_{i}\right)=\frac{R+\hat{\tau}(1-\phi)\left(a+\left(n-x_{i}\right) A\right) / x_{i}}{1-\beta} \text { for } i \in\{m, h\},
$$

which takes into account that incomes are reduced by a fraction $\phi$, because the military is running the economy, and only $n-x_{i}$ citizens are working in production. The proceeds from taxation are distributed equally among the soldiers, thus the division by $x_{i}$ in the denominator. 
Consider next the case where $x=x_{h}$ (with $s=D$ ). If the elite do not prevent coups, the value to the military is $V^{M}\left(D, x_{h} \mid \operatorname{coup}\right)=V^{M}\left(M, x_{h}\right)$ as given by equation (5) for $i=h$. Alternatively, the elite could pay an "efficiency wage" to the soldiers, $w_{h}^{P}$, to make it worth for them not to attempt coups-namely, to satisfy the no coup constraint (4). When $x=x_{h}$, the expression for the efficiency wage is straightforward to derive, because there is no possibility of reforming the military. Therefore, the value to the military when the elite pay such a wage is $V^{M}\left(D, x_{h} \mid\right.$ no coup $)=w_{h}^{P}+\beta V^{M}\left(D, x_{h} \mid\right.$ coup $)$, where $w_{h}^{P}$ is the level of the efficiency wage that makes equation (4) hold as equality, and this expression takes into account that in the next period the military must receive the value that it can get with a coup (either by undertaking a coup, or because the elite will pay them the necessary efficiency wage). This implies that the efficiency wage will be $w_{h}^{P}=\hat{\tau}(1-\phi)\left(a+\left(n-x_{h}\right) A\right) / x_{h}+R$, and the tax rate that satisfies the government budget constraint in this case is

$$
\tau_{h}^{P}=\hat{\tau}(1-\phi)+\frac{x_{h} R}{a+\left(n-x_{h}\right) A} .
$$

However, it may not be feasible for the civilian government to pay such high wages to soldiers because in the government budget constraint (1) we need to have $\tau \leq \hat{\tau}$. Hence, coup prevention with an army of size $x_{h}$ is feasible only if $w_{h}^{P} x_{h} \leq \hat{\tau}\left(a+\left(n-x_{h}\right) A\right)$. This implies that coups starting with $x=x_{h}$ can be prevented provided that

$$
\phi \geq \frac{x_{h} R}{\hat{\tau}\left(a+\left(n-x_{h}\right) A\right)} \equiv \phi_{h}^{*} .
$$

Let us next consider the case where $x=x_{m}$ (again with $s=D$ ). If the elite prevent coups by paying an efficiency wage $w_{m}^{P}$, then the value to each soldier is ${ }^{5}$

$$
V^{M}\left(D, x_{m} \mid \text { no coup }\right)=w_{m}^{P}+\beta\left[\lambda V^{L}\left(D, x_{\ell}\right)+(1-\lambda) V^{M}\left(D, x_{m} \mid \text { coup }\right)\right],
$$

which now takes into account that with probability $\lambda$ there will be an opportunity to reform and downsize the military, and the civilian government will use this opportunity, and thereafter, soldiers will receive the value $V^{L}\left(D, x_{\ell}\right)$ as given by equation (3). If there is no opportunity to reform, then the soldiers will receive the value from a coup (either because they will undertake a coup or because the no coup constraint (4) will be satisfied with equality). Using equations (3) and (4), we can compute

$$
V^{M}\left(D, x_{m} \mid \text { no coup }\right)=\frac{w_{m}^{P}+\frac{\beta}{1-\beta} \lambda\left(1-\tau_{\ell}\right) A}{1-\beta(1-\lambda)} .
$$

5. This is the value of soldiers after the realization of the state of nature that the military cannot be reformed. 
The value from a coup is given by equation (5). Repeating the same analysis as previously, we find that with an army of size $x=x_{m}$, it will be feasible to satisfy the no coup constraint (4) only when

$$
\phi \geq \frac{\beta \lambda}{1-\beta(1-\lambda)}\left[1-\frac{\left(1-\tau_{\ell}\right) x_{m} A}{\hat{\tau}\left(a+\left(n-x_{m}\right) A\right)}\right]+\frac{x_{m} R}{\hat{\tau}\left(a+\left(n-x_{m}\right) A\right)} \equiv \phi_{m}^{*} .
$$

To save space, in the remainder, we impose the following assumption, which allows us to focus on the more novel and economically interesting cases.

AsSUMPTION 1.

(1) $R_{m}<R \leq \bar{R}_{h}$, where $\bar{R}_{h} \equiv \hat{\tau}\left(a+\left(n-x_{h}\right) A\right) / x_{h}$ and $R_{m} \equiv \beta A(1-$ $\left.x_{\ell} A /(a+n A)\right)+(1-\beta) \hat{\tau}\left(a+\left(n-x_{m}\right) A\right) / x_{m}$.

(2) $\phi \in\left[\phi_{h}^{*}, 1\right]$ and $\lambda \in\left(\lambda^{*}, 1\right]$.

(3) $\beta>\beta^{*}$, where $\beta^{*}<1$ is implicitly defined by the following equation:

$$
\begin{aligned}
\beta^{*} A\left(1-x_{\ell} A /(a+n A)\right)+\left(1-\beta^{*}\right) \hat{\tau}\left(a+\left(n-x_{m}\right) A\right) / x_{m} & \\
& =\hat{\tau}\left(a+\left(n-x_{h}\right) A\right) / x_{h} .
\end{aligned}
$$

The first part of Assumption 1 states that military rents in a military dictatorship are intermediate, so that military dictatorships are not desirable when soldiers know that they will have sufficient influence in the civilian regime, that is, they will receive efficiency wages without any risk of downsizing, but are worthwhile when they do not receive efficiency wages. More specifically, $R \leq \bar{R}_{h}$ ensures that $\phi_{h}^{*} \leq 1$ so that for values of $\phi \in\left[\phi_{h}^{*}, 1\right]$ it will be feasible to satisfy equation (4) and to prevent coups with an over-sized army $\left(x=x_{h}\right)$. In contrast, $R_{m}<R$ ensures that preventing coups with an intermediate-sized army $\left(x=x_{m}\right)$ is not feasible when the probability of potential reform, $\lambda$, is sufficiently high (i.e., $\phi_{m}^{*}>1$ as $\lambda$ approaches to 1$)$. In particular, let $\lambda^{*}$ be defined as the value of $\lambda$ such that $\phi_{m}^{*}=1$. Then this assumption implies that when $\lambda \in\left(\lambda^{*}, 1\right]$, equation (8) can never be satisfied and coups cannot be prevented with an intermediatesized army. The second part of the assumption then imposes that $\phi \in\left[\phi_{h}^{*}, 1\right]$ so that prevention of coups with an over-sized military is indeed feasible, and $\lambda \in\left(\lambda^{*}, 1\right]$ so that coup prevention with an intermediate-sized military is never feasible. Finally, the third part of the assumption ensures that $R_{m}<\bar{R}_{h}$, so that the first part of the assumption is meaningful.

Note that the expected value to the elite when there is a civil war and $x=x_{\ell}$ is:

$$
V^{E}\left(W, x_{\ell}\right)=\left(1-\bar{\tau}_{\ell}\right)(1-\delta) a+\bar{r}+\beta\left[p V^{E}\left(D, x_{\ell}\right)+(1-p) V^{E}\left(W, x_{\ell}\right)\right],
$$


where $\bar{\tau}_{\ell}$ is given by equation (2) and $\bar{r}$ is the elite's rent when they are in power but there is an ongoing civil war. This expression incorporates the fact that the rebels are defeated with probability $p=p\left(x_{\ell}\right)$ in each period, and subsequently the continuation value to the elite is $V^{E}\left(D, x_{\ell}\right)=\left(\left(1-\tau_{\ell}\right) a+r\right) /(1-\beta)$, where $r$ is their rent from power without a civil war (since an army of size $x_{\ell}$ cannot attempt a coup, $s=D$ with $x=x_{\ell}$ is an absorbing state). Therefore:

$$
V^{E}\left(W, x_{\ell}\right)=\frac{(1-\beta)\left(\left(1-\bar{\tau}_{\ell}\right)(1-\delta) a+\bar{r}\right)+\beta p\left(\left(1-\tau_{\ell}\right) a+r\right)}{(1-\beta)(1-\beta(1-p))} .
$$

Given Assumption 1, when the elite choose an army of size $x=x_{m}$, then coups cannot be prevented, and thus their value can be written as

$$
\begin{aligned}
V^{E}\left(W, x_{m}\right)= & \left(1-\bar{\tau}_{m}\right)(1-\delta) a+\bar{r} \\
& +\beta\left[\frac{\lambda\left(\left(1-\tau_{\ell}\right) a+r\right)}{1-\beta}+\frac{(1-\lambda)(1-\hat{\tau})(1-\phi) a}{1-\beta}\right],
\end{aligned}
$$

where $\bar{\tau}_{m}$ is given by equation (2). This expression takes into account that rebels are defeated in one period and, in the following period, the army is reformed with probability $\lambda$, while reforms are not possible with the complementary probability and the military undertakes a coup.

Finally, if the elite choose $x=x_{h}$, their value depends on whether coups will be prevented in the subgame starting after the defeat of the rebels. Assumption 1 implies that prevention is feasible and optimal. Hence, the value to the elite in this case is

$$
V^{E}\left(W, x_{h}\right)=\left(1-\bar{\tau}_{h}\right)(1-\delta) a+\bar{r}+\beta \frac{\left(1-\tau_{h}^{P}\right) a+r}{1-\beta} .
$$

In light of this discussion, the potential strategies for the elite are: (1) form an over-sized military $\left(x_{h}\right)$, defeat the rebels, and prevent coups, thus remaining in power but with a very influential military; (2) form an intermediate army $\left(x_{m}\right)$, defeat the rebels, but face the risk of military takeover; (3) choose a small army $\left(x_{\ell}\right)$, and thus allow for persistent civil war.

To compare these three options, note that $V^{E}\left(W, x_{\ell}\right)=V^{E}\left(W, x_{\ell} \mid p\right)$ defined in equation (9) is a strictly increasing function of the probability $p$ that a small army $\left(x_{\ell}\right)$ will defeat the rebels (hence the explicit conditioning on $p$ ), and $V^{E}\left(W, x_{h}\right)$ and $V^{E}\left(W, x_{m}\right)$ defined in equations (10) and (11) are independent of $p$. This implies that there exists a threshold $\hat{p} \in[0,1]$ such that $V^{E}\left(W, x_{h}\right) \gtreqless$ $V^{E}\left(W, x_{\ell} \mid p=\hat{p}\right)$ whenever $p \lesseqgtr \hat{p}$, and a threshold $p^{*} \in[0,1]$ such that $V^{E}\left(W, x_{m}\right) \gtreqless V^{E}\left(W, x_{\ell} \mid p=p^{*}\right)$ whenever $p \lesseqgtr p^{*}$. It can be verified that both thresholds are always smaller than 1 , because the value to the elite when $x=x_{\ell}$ and $p=1$ is always greater than their value when choosing $x_{h}$ and $x_{m}$. 
However, these thresholds need not be positive. In particular, $\hat{p}>0$ only when $V^{E}\left(W, x_{h}\right)>V^{E}\left(W, x_{\ell} \mid p=0\right)$, that is, when

$$
\left(1-\bar{\tau}_{\ell}\right)(1-\delta) a<(1-\beta)\left(1-\bar{\tau}_{h}\right)(1-\delta) a+\beta\left(1-\tau_{h}^{P}\right) a+\beta(r-\bar{r}) .
$$

Otherwise $V^{E}\left(W, x_{h}\right)<V^{E}\left(W, x_{\ell}\right)$ for all $p \in[0,1]$, and in this case, a small army $\left(x_{\ell}\right)$ will always be preferred by the elite to an over-sized one $\left(x_{h}\right)$, and by convention, in this case we set $\hat{p}=0$. Similarly, $p^{*}>0$ when

$$
\begin{aligned}
\left(1-\bar{\tau}_{\ell}\right)(1-\delta) a<(1-\beta)\left(1-\bar{\tau}_{m}\right)(1-\delta) a+\beta \lambda\left(1-\tau_{\ell}\right) a & \\
& +\beta(1-\lambda)(1-\hat{\tau})(1-\phi) a+\beta(\lambda r-\bar{r}),
\end{aligned}
$$

and thus when this condition is not satisfied, the elite always prefer $x_{\ell}$ to $x_{m}$. In what follows, the reader should bear in mind that both thresholds, $\hat{p}$ and $p^{*}$, can be zero.

Let us finally introduce the following condition:

$$
\begin{aligned}
& \left(\bar{\tau}_{h}-\bar{\tau}_{m}\right)(1-\delta) a \\
& \quad \leq \frac{\beta}{1-\beta}\left[(1-\lambda)(r+\phi a)+\left(\tau_{\ell}-\hat{\tau}(1-\phi)\right) \lambda a-\frac{x_{h} a}{a+\left(n-x_{h}\right) A} R\right] .
\end{aligned}
$$

It can be verified that when this condition is satisfied, $V^{E}\left(W, x_{h}\right)>V^{E}\left(W, x_{m}\right)$, and the elite prefer an over-sized army to an intermediate one.

We now provide a characterization of the MPE in this dynamic economy. ${ }^{6}$

Proposition 1. The political game herein has a unique MPE with the following structure.

1. Suppose that equation (14) is satisfied and $p \in[\hat{p}, 1]$ or that equation (14) is not satisfied and $p \in\left[p^{*}, 1\right]$. Then the elite choose a small army, $x=x_{\ell}$, and there is persistence of civil war. After (or if) the civil war ends, the civilian government (the elite) remains in power.

2. Suppose that (14) does not hold and $p \in\left[0, p^{*}\right)$, then the elite choose an intermediate-sized army, $x=x_{m}$, and the civil war ends immediately, but there is possibility of a military coup and the formation of a military dictatorship.

3. Suppose that condition (14) is satisfied and $p \in[0, \hat{p})$, then the elite choose an over-sized army, $x=x_{h}$, the civil war ends immediately, and civilian government remains in power, but with high wages and concessions for the military.

6. The argument in the text gives the main idea of the proof of this proposition. A more detailed characterization of the MPE and a formal proof are provided in the online Appendix. 
COROLlaRy 1. $\quad \hat{p}$ is nondecreasing in $r, \delta, \phi$, and it is nonincreasing in $\bar{r}, \hat{\tau}, x_{h}, R$.

$p^{*}$ is nonincreasing in $\bar{r}, \hat{\tau}, \phi, x_{m}$, is independent of $R$, and is nondecreasing in $\delta$, and also in $r$ if $\lambda$ is high enough and nonincreasing in $r$ otherwise.

Proposition 1 is the main result of the paper. It shows that the elite will choose a small army (see point 1), and will not establish a monopoly of violence over its territory, at least for a while, when $p>\hat{p}$ or when $p>p^{*}$-that is, when a small army is not too ineffective at fighting the rebels. Note, however, that both thresholds $\hat{p}$ and $p^{*}$ can be very small or equal to zero, so when a small army is maintained, the civil war can persist for a very long time (in the limit forever as $p \rightarrow 0$, if both thresholds are zero). Corollary 1 shows that such an outcome is more likely when $r$ is low relative to $\bar{r}$, that is, when the elite receive significant rents even when the civil war is ongoing (for example because the civil war is in peripheral areas and does not interfere with the rents that the elite receive from corruption or natural resources). Small armies and persistent civil wars are also more likely when $\delta$ is low relative to $\phi$, making the income loss (of the elite and of the citizens) relatively small under civil war, and high under military regimes. Finally, a high $\hat{\tau}$ also makes this configuration more likely via two channels: First, it makes a military dictatorship more costly to the elite (when this happens along the equilibrium path); second, it makes a military dictatorship more attractive for soldiers, thus making it more expensive for the elite to satisfy the no coup constraint (when they prefer to do so). For reasons related to the second channel, a high level of $R$ (high rents for the military from controlling the government) also makes the elite more likely to choose a small army and a weak state. In all cases, the reason why the elite prefer a small army is that they are afraid of the influence of and a potential coup by a strong army following the end of the civil war.

When the elite decide to fight the rebels more vigorously to end the civil war, they can do so using one of two different strategies. In the first one, they build an intermediate-sized army, but because of their inability to commit to not downsizing the army after the civil war ends, they cannot satisfy the no coup constraint, and there is a positive probability of a coup along the equilibrium path. In the second one, they build an over-sized army as a commitment to not reforming the military in the future. This amounts to making permanent concessions (high wages and other policy concessions) to the military as the price that the elite have to pay for fighting the rebels and establishing some sort of monopoly of violence. Note, however, that in this case this monopoly of violence is mostly in the hands of the military not in the hands of the civilian government.

An interesting implication of the model, again highlighted by Corollary 1, is a novel substitutability between fiscal and political capacity of the state. When $\hat{\tau}$ is high, the fiscal capacity of the state is high. This is generally thought to increase 
the political capacity of the state (e.g., Besley and Persson 2009). However, a higher fiscal capacity also puts more economic power in the hands of the military if they decide to attempt a coup. Through this channel, it discourages the civilian government from building a strong military and the monopoly of violence necessary for political capacity.

Finally, it is also useful to observe that the entire analysis is predicated on the possibility that the military, once sufficiently large, can take control of the government. In this sense, the model represents the workings of politics in a weakly-institutionalized polity, which does not place major constraints on the exercise of military power.

\section{Concluding Remarks}

We presented a simple model where civil wars persist because of the endogenous weakness of the state. The civilian government, assumed to be under the control of an elite, may prefer to forgo the establishment of the monopoly of violence over its territory, allowing an ongoing civil war, because, given the weak institutions, the elite are afraid of building a strong military. This fear is particularly relevant when the civilian government is unable to commit to not reforming the military after the civil war is over, and this commitment problem makes a military coup more likely. One, potentially paradoxical, response of the civilian government, when it needs to prevent the continuation of the civil war, is to build an over-sized army as a commitment to not reforming the military after the threat of the civil war is gone.

\section{References}

Acemoglu, Daron (2005). "Politics and Economics in Weak and Strong States." Journal of Monetary Economics, 52, 1199-1226.

Acemoglu, Daron, and James A. Robinson (2006). Economic Origins of Dictatorship and Democracy. Cambridge University Press.

Acemoglu, Daron, James A. Robinson, and Thierry Verdier (2004). "Kleptocracy and Divideand-Rule: A Model of Personal Rule." Journal of the European Economic Association, 2, 162-192.

Acemoglu, Daron, Davide Ticchi, and Andrea Vindigni (2010a). "A Theory of Military Dictatorships." American Economic Journal: Macroeconomics, 2, 1-42.

Acemoglu, Daron, Davide Ticchi, and Andrea Vindigni (2010b). "Emergence and Persistence of Inefficient States." Forthcoming Journal of the European Economic Association.

Besley, Timothy, and Torsten Persson (2009). "The Origins of State Capacity: Property Rights, Taxation and Politics." American Economic Review, 99, 1218-1244.

Besley, Timothy, and James A. Robinson (2010). "Quis Custodiet Ipsos Custodens: Civilian Control over the Military.” Journal of the European Economic Association, 8(2-3), 655-663.

Blattman, Christopher, and Edward Miguel (2010). "Civil War." Journal of Economic Literature, forthcoming.

Fearon, James D. (2007). “Why Do Some Civil Wars Last so Long?” Journal of Peace Research, $41,275-302$. 
Fearon, James D., and David Laitin (2003). "Ethnicity, Insurgency, and Civil War." American Political Science Review, 97, 75-90.

Herbst, Jeffrey (2004). "African Militaries and Rebellion: The Political Economy of Threat and Combat Effectiveness." Journal of Peace Research, 41, 357-369.

Hironaka, Ann (2008). Neverending Wars: The International Community, Weak States, and the Perpetuation of Civil War. Harvard University Press.

Owen, Roger (2004). State, Power and Politics in the Making of the Modern Middle East. Rutledge.

Powell, Robert (2004). "Bargaining and Learning While Fighting." American Journal of Political Science, 48, 344-361.

Yared, Pierre (2009). "A Dynamic Theory of War and Peace." Working paper, Columbia University. 